\title{
Relato de Intervenção em Psicologia: identidade social do agente comunitário de saúde
}

Psychology Intervention Report: social identity of the community health agent

\author{
Flávio Martins de Souza Mendes \\ Psicologo. Mestrando do Programa de Pós Graduação em Psico- \\ logia da Universidade Federal do Espírito Santo. \\ Endereço: Rua Maria Eleonora Pereira, n I25, ap. 203, Bairro Jardim \\ da Penha, CEP 29060-180, Vitória, ES, Brasil. \\ E-mail: flaviomsmendesळyahoo.com.br \\ Eduardo Coelho Ceotto \\ Doutorando do Programa de Pós-graduação em Psicologia da \\ Universidade Federal do Espírito Santo (PPGP/UFES). Docente da \\ Faculdade Brasileira - UNIVIX. \\ Endereço: Rua Natalina Daher Carneiro, n 860, ap. 204, Bairro \\ Jardim da Penha, CEP 29060-490, Vitória, ES, Brasil. \\ E-mail: edu.ceotto®gmail.com
}

\section{Resumo}

A profissão de Agente Comunitário de Saúde (ACS) é ainda nova no Sistema Único de Saúde (SUS). Em função disso, percebe-se a existência de certas dificuldades na compreensão da identidade desses profissionais, pela sua característica de atuar como elo da Unidade Básica de Saúde (UBS) com a comunidade. $\mathrm{O}$ objetivo deste trabalho é relatar uma intervenção em Psicologia realizada com Agentes Comunitários de Saúde de uma UBS da região continental de Vitória (ES). A intervenção teve como intuito identificar aspectos da identidade social que interferem na qualidade de vida e no trabalho desses profissionais. Foram realizadas 15 oficinas com média de 11 participantes, entre junho e dezembro de 2008. Algumas questões foram percebidas no grupo: dificuldade de interação entre si e com os demais profissionais da unidade; pouco sentimento de pertença; baixa auto-estima; dificuldade em construir alternativas para mudança. Com o trabalho realizado pela Psicologia, foi possível perceber mudanças na forma como as agentes lidavam com os problemas do dia a dia, pensando no grupo de maneira mais coletiva, percebendo sua profissão como importante para o SUS, o que permitiu, apesar das questões inerentes à prática profissional, construir estratégias para lidar com suas dificuldades e promover qualidade de vida no trabalho.

Palavras-chave: Agente Comunitário de Saúde; Psicologia social da saúde; Identidade social. 


\section{Abstract}

The profession of Community Health Agent (ACS) is still new in Brazil's National Health System (SUS). Therefore, it is perceived that there are certain difficulties in the comprehension of this professional's identity, due to his characteristic of acting as a link between the Primary Healthcare Unit (UBS) and the community. The objective of this article is to report on an intervention in Psychology carried out with Community Health Agents from a UBS located in the continental region of Vitória (Southeastern Brazil). The intervention aimed to identify social identity aspects that interfere in the quality of life and in the work of this professional. Fifteen workshops with an average of eleven participants were held between the months of June and December of 2008. Some questions were perceived in the group: interaction difficulties within the group and with the other professionals from the unit; low sense of belonging; low self-esteem; difficulty in constructing alternatives of change. With the work done by the Psychology, it was possible to perceive changes in the way that the agents dealt with the daily problems, thinking of the group in a collective way and perceiving their profession as something important to the SUS. This enabled, despite the questions inherent in the professional praxis, to construct strategies to deal with the difficulties and promote quality of life in the workplace.

Keywords: Community Health Agent; Social Psychology of Health; Social Identity.

\section{Introdução}

O Sistema Único de Saúde (SUS) tem mostrado avanços contínuos desde sua estruturação na década de 1980. Idealizado e construído pelos reformistas junto à população, referendado nos debates ocorridos na $8^{a}$ Conferência Nacional de Saúde, em 1986, e escrito na Constituição de 1988, o SUS ganha espaço cada vez maior seguindo seus princípios de universalidade, integralidade e equidade, e suas diretrizes de descentralização, regionalização e hierarquização, assim como com a inegável intervenção do controle social (Negri, 2002; Vasconcelos e Pasche, 2006).

Esse novo modo de pensar a saúde, com base em princípios e diretrizes, estimulou a valorização da atenção primária, tendo o Programa de Saúde da Família (PSF), atualmente Estratégia de Saúde da Família (ESF), como uma das suas estratégias mais importantes em expansão. No entanto, para que fosse possível a consolidação desse programa e o enfrentamento dos índices de morbimortalidade infantil e materna na região nordeste à época, necessitou-se constituir o Programa de Agentes Comunitários de Saúde (Pacs), inserindo o SUS nas comunidades, fixando os enfermeiros no interior e dando importância aos aspectos culturais de cada região, inserindo líderes comunitários nas políticas públicas (Souza, 2002).

O Agente Comunitário de Saúde (ACS) é um profissional constituído com o objetivo de ser o elo entre a comunidade em que vive e a unidade em que trabalha. Já nesta premissa um conflito fica claro: como um sujeito, um profissional, realizará esta função de entremeio, de usuário e profissional de saúde?

Junto a este "elo" associam-se outros atributos, como a ideia de agente transformador, agente de mudanças e de profissional da saúde, que dão ao antigo usuário do serviço um novo status em sua comunidade, ao mesmo tempo de prestígio por ser o "tradutor" das questões de sua área e, também em função disso, de sofrimento (Nunes e col., 2002; Jardim, 2007; Martines e Chaves, 2007).

0 sofrimento se estabelece à medida que esse profissional percebe que, apesar de agente transformador, não tem as ferramentas necessárias, o conhecimento, nem todo este atributo de mudança 
que acompanha a teoria sobre sua função. Estar em sua comunidade como profissional o coloca, portanto, nesse pêndulo entre o que é real do local em que vive e o que de fato pode ser feito para a sua melhoria, mesmo com a teoria sobre a qual se constituiu como um agente da comunidade e da saúde (Nunes e col., 2002; Jardim, 2007; Martines e Chaves, 2007).

Desta forma, cabe pensar a respeito da discussão sobre a identidade do Agente Comunitário de Saúde, que pode ser visto como um personagem híbrido e polifônico. Estar entre a UBS e a comunidade é um dos fatores que tende a provocar sofrimento no trabalho. Com isso, a compreensão acerca da construção e da manutenção da identidade do ACS torna-se importante, principalmente levando-se em consideração as discussões atuais sobre a saúde dos profissionais de saúde.

Silva e Dalmaso (2002) realizaram uma pesquisa com diversos atores da saúde. 0 estudo teve como objetivo identificar o que é ser ACS, quais são suas funções, suas questões, tentando obter informações desse profissional de papel indefinido. 0 trabalho buscou conhecer categorias para caracterização do ACS na cidade de São Paulo para discutir o perfil desse profissional e comparar com o encontrado em outros estudos.

As autoras apresentam quatro dimensões que se relacionam formando a identidade ocupacionalsocial do ACS: 1) referente à profissão, o saber e a regulamentação; 2) relacionada à identidade e organização do trabalho, transitando entre os polos burocrático e profissional, as regras e o respaldo social; 3) referente à identidade no pertencer a um determinado grupo, diferente de outro, tentando identificar o que determina a coesão interna e a sua diferenciação; 4) relativa às características dos modos de assistência na saúde e as funções dos profissionais (Silva e Dalmaso, 2002).

Silva e Dalmaso (2002) concluem retomando a discussão acerca da ambiguidade da identidade do agente entre o lado institucional/técnico e comunitário/político; da dificuldade em clarear o ser e o fazer, visto ser diferente dos serviços tradicionais; do desgaste em ter que realizar escolhas em função das situações cotidianas; da tensão devido a essas escolhas; da falta de tecnologias e saberes para cor- responder às expectativas de todos, o que retorna ao tema da identidade híbrida.

As autoras concluem sugerindo que novos estudos sejam realizados sobre a identidade dos agentes, que parecem sofrer devido às expectativas que carregam tanto pelos demais profissionais da saúde quanto pelos usuários da comunidade. Apesar dos dados encontrados, deixam em aberto a questão do que pode ser feito, apesar das quatro dimensões pensadas como constituintes da identidade do ACS.

O trabalhador ACS se expõe a diversos fatores de sobrecarga em seu trabalho, prejudicando a qualidade com que realiza suas atividades e, consequentemente, sua qualidade de vida. Problemas em relação à carga horária de trabalho, às metas a serem cumpridas, à privacidade e liberdade, ao local de moradia, à interação com os demais profissionais e com moradores da comunidade são alguns dos fatores que se colocam como dificultadores do trabalho do ACS (Wai, 2007).

No tocante aos trabalhos desenvolvidos com os agentes comunitários, observa-se uma predominância na descrição das atividades desenvolvidas, bem como os conhecimentos, percepções e representações sobre o trabalho. Apesar da quantidade de fatores de sobrecarga, poucas são as informações relativas às intervenções realizadas com o intuito da melhoria das condições de trabalho desses profissionais a partir de uma visão ampliada das mesmas. (Nunes e col., 2002; Kluthcovsky e Takayanagui, 2006; Jardim, 2007; Martines e Chaves, 2007; Bornstein e Stotz, 2008).

Em função das constantes reflexões e da mudança de paradigmas devido à entrada na área da saúde, atualmente tem cabido ao psicólogo, que atua neste âmbito, refletir a respeito dos processos humanos, "pensar" saúde em seu conceito amplo, não restrito ao corpo biológico, mas também às questões psicológicas e sociais, não em busca de uma completude, mas da constante construção da própria concepção de saúde (Spink, 2003).

A psicologia, segundo Spink (2003), tem o compromisso com os direitos sociais a partir de uma ótica coletiva, dialogando com teorias que considerem a vida e os sujeitos de maneira relacional, pesquisando e atuando nos níveis de atenção e na 
comunidade, sobretudo com questões de prevenção de doenças e promoção da saúde. Além disso, tendo participação em conselhos de saúde, comissões, fóruns e outros espaços para reflexão e construção de políticas públicas.

Juntamente, traz uma prerrogativa de se pensar o conceito de saúde evitando o aprisionamento à ideia de saúde focada na ausência de doenças, levando em consideração o fato de que saúde e doença fazem parte de um mesmo processo vital. Essa perspectiva valoriza os aspectos biológicos, psicológicos e sociais em constante interação com o meio ambiente, o momento histórico, a cultura e as possibilidades de cada sujeito (Czeresnia, 2003).

Para Canguilhem (1990), saúde deve ser pensada como normatividade, ou seja, como a capacidade de criar novas normas de acordo com as possibilidades de cada sujeito em relação às interações em relação a si próprio e às pessoas ao redor. Significa dizer que a noção de doença também é uma norma, porém uma norma que aprisiona o sujeito, não permitindo que este se renove, ou seja, não possibilitando a construção de novas normas.

Pensando nessa concepção acerca do processo saúde/doença e considerando a atividade realizada pelos ACS, este trabalho tem por objetivo relatar a experiência de uma intervenção em Psicologia realizada com Agentes Comunitários de Saúde. De forma mais específica, a intervenção teve como objetivo identificar aspectos da identidade dos ACS que interferem na qualidade de vida no trabalho, partindo da verificação da interação dos ACS, conhecendo as relações interpessoais, averiguando fatores que dificultam ou facilitam o trabalho e fortalecendo o sentimento de pertença.

O presente trabalho é resultado do programa de estágio supervisionado em psicologia social comunitária, desenvolvido em Unidades Básicas de Saúde na região continental no município de Vitória (ES). A abordagem prática busca demonstrar a relevância da intervenção psicológica junto às ações desenvolvidas na comunidade. 0 enfoque teórico baseado na psicologia social da saúde (Spink, 2003) fortalece a formação do psicólogo no sentido de fornecer ferramentas para a intervenção e a construção de novas normas junto aos ACS. Por outro lado, possibilita refletir a respeito da identidade desse profissional.

\section{Metodologia}

A proposta teve início em 2007 com a inserção de um grupo de estudantes estagiários em Unidades Básicas de Saúde (UBS). O primeiro passo na aproximação a essa realidade é feito de forma a levantar as demandas advindas dos profissionais que atuam na UBS, nas quais os ACS estão inseridos. No momento de inserção na UBS, é solicitado que seja feita uma intervenção junto aos ACS uma vez que a dificuldade no relacionamento entre eles estava afetando a qualidade do serviço prestado pela UBS.

$\mathrm{O}$ primeiro semestre de atuação serviu para abrir espaço para a atuação dos estagiários, além de fortalecer o vínculo entre a instituição de ensino e a UBS. Nesse primeiro momento, os estagiários acompanharam as atividades desenvolvidas pelos psicólogos das UBS para no segundo semestre de atividade desenvolverem um projeto. Nesse caso, o projeto teve por objetivo realizar uma intervenção junto aos ACS. A queixa da coordenação da equipe era de que os ACS se mantinham isolados dos demais profissionais da UBS, com problemas nas relações interpessoais e com dificuldades em cumprir as determinações da gerência.

\section{Identificação da população}

O grupo de ACS da UBS era composto por 19 pessoas (18 mulheres e um homem), no entanto, como a participação não era obrigatória, as atividades se desenvolveram com uma média de 11 participantes. A equipe de ACS está formada desde 2002, e observa-se baixa rotatividade entre seus membros.

\section{Descrição das Oficinas}

Foram desenvolvidas 15 oficinas entre junho e dezembro de 2008. As oficinas podem ser divididas em três fases. A primeira fase possibilitou conhecer e abrir espaço para a realização dos trabalhos na UBS; a segunda caracterizou-se pela sensibilização para as mudanças dentro do grupo de agentes; e a terceira, concluindo as ações, solidificou as mudanças a partir das práticas, ações propositivas, dentre outras. Os encontros tiveram duração média de uma hora.

As atividades foram realizadas com técnicas de dinâmica de grupo e discussões temáticas como disparadores, visando propiciar o conhecimento, a 
interação e a intervenção. Dessa forma, foi possível realizar uma aproximação dos estagiários com o grupo, efetivar as oficinas e, por fim, avaliar o processo de intervenção.

\section{Resultados: as Oficinas}

A seguir serão apresentados, discutidos e analisados os resultados obtidos a partir das oficinas realizadas.

\section{Quadro I - Fase I - Conhecendo/Abrindo espaço para a realização do trabalho}

\begin{tabular}{ll|}
\hline $\begin{array}{l}\text { Fase I } \\
\text { Conhecendo/Abrindo espaço para a realização do trabalho }\end{array}$ & Oficina I - Vinculação e levantamento de expectativas \\
\hline Oficina 2 - Construção das regras do trabalho (contrato) \\
\hline Oficina 3 - Discussão sobre trabalho e gênero \\
\hline Oficina 4 - Reflexão sobre papéis dos ACS \\
\hline
\end{tabular}

A primeira fase das oficinas teve por objetivo conhecer e abrir espaço para a realização da intervenção. Nesta, foram identificadas as principais questões a serem trabalhadas com o grupo: dificuldade de interação entre si e com os demais profissionais e usuários, pouco sentimento de pertença ao grupo e em relação à profissão, baixa auto-estima, dificuldade em buscar alternativas para enfrentar seus problemas.

Durante essa fase (Quadro 1), que pode ser entendida como de diagnóstico, de conhecimento dessa realidade, foram realizadas discussões baseadas nos temas identificados nas primeiras oficinas. Como exemplo, podem-se citar: dupla jornada de trabalho (na Unidade e em casa), dificuldade no relacionamento interpessoal, fragilidade das pessoas que ali estão trabalhando, em se tratando da maneira como compreendiam e lidavam com as situações vivenciadas no trabalho. Uma das solicitações do grupo fora que as oficinas acontecessem em espaços diferentes dos da UBS.

Com relação às regras de funcionamento do grupo, foi estabelecido um contrato em que, a partir de uma pergunta disparadora "O que queremos e o que não queremos para o grupo?”, os ACS indicaram as

\section{Quadro 2 - Fase 2-Sensibilizando para as mudanças}

Fase 2

Sensibilizando para as mudanças regras para o funcionamento das oficinas. As ideias eram anotadas para que, ao final, fosse escolhido o que ficaria e o que não ficaria no contrato, o que se mostrou como uma das intervenções mais produtivas no projeto, uma vez que o grupo passou a se organizar melhor, participando mais efetivamente das oficinas, chegando no horário marcado, pedindo silêncio e respeito quando preciso, ou seja, o grupo se comprometeu com a realização das atividades.

A construção do contrato estabeleceu certo vínculo entre todos e organizou um conjunto de regras para que as atividades acontecessem, bem como delimitou o que era aceito ou não pelo grupo e as funções dos participantes. A partir desse momento foi possível a visualização das características das pessoas que compõem aquele grupo, ou seja, as características das pessoas interferindo naquele momento, positiva ou negativamente.

Dessa forma, surgiu então a necessidade de pensar o lugar das pessoas na função de ACS, a maneira como trabalham, as relações que constroem a cada dia, aquilo que produz algum tipo de sofrimento ou aquilo que traz qualidade de vida para o trabalho.

A partir daí, deu-se início à Fase 2 que tinha por objetivo a sensibilização do grupo para as mudanças.

Oficina 5 - Problematizando as funções do ACS

Oficina 6 - Debate sobre papéis dos profissionais

Oficina 7 - Discussão sobre ESF, PACS e ACS

Oficina 8 - Reflexão sobre responsabilidade × culpa

Oficina 9-Debate sobre dificuldades no/do trabalho

Oficina 10 - Construção de vivências em equipe 
A cada semana eram realizadas discussões a respeito dos temas sugeridos e outros julgados importantes para a reflexão no grupo. Nos momentos em que as reclamações passavam a ser recorrentes, houve intervenções com reflexões, dinâmicas e vivências como, por exemplo, a Oficina 5 ("Problematizando as funções do ACS”). Nessa oficina, o grupo foi dividido em dois. Um atuava em defesa da profissão e outro contra. Suas funções seriam defender e acusar a partir da reflexão: "Deve ou não existir agente de saúde na unidade?".

Tal atividade permitiu que o grupo refletisse sobre pontos positivos e negativos da profissão, debatendo entre si facilidades e dificuldades em sua prática cotidiana, na interação, na relação com a unidade e com a comunidade. 0 debate ocasionou um julgamento, no qual duas integrantes, uma na posição de defesa e a outra na de acusação, julgaram o próprio grupo, citando pontos positivos e negativos e justificando-os. Ao final, foi aberto espaço para que falassem da experiência de defender e acusar sua própria atividade, processo que se mostrou frutífero, em se tratando de sentimento de pertença, de identidade. Essa atividade foi importante tanto para os ACS, que podiam falar da própria profissão (atividade, trabalho), quanto para os estagiários, pois permitiu avaliar o trabalho e adequar esse discurso na proposta de intervenção.

Além dos pontos discutidos, cabe retomar a ideia de que a função do agente de saúde é servir de elo entre unidade e comunidade. Vários agentes reclamaram não poder fazer muito pela comunidade, uma vez que não diagnosticam, não medicam, não marcam consultas, ou seja, não fazem o mesmo que os outros profissionais. Algumas falas dos agentes, durante a oficina, referem-se a essa questão: "Se não pode fazer nada, o que veio fazer aqui? O que faz?", "Não resolve nada para o usuário" (fala de agentes na Oficina 5).

Segundo Nunes e colaboradores (2002), Jardim (2007) e Martines e Chaves (2007), os ACS são colocados na posição de agentes de mudanças inseridos na comunidade. Além destes, Silva e Dalmaso (2002) dizem que a identidade do ACS é menos clara por não ser um serviço tradicional, tendo que se adaptar sempre às diferentes situações que lhes aparecem, uma vez que ser esse agente de mudanças carrega consigo a angústia de não ver ou ver poucas mudanças ocorrerem, muitas vezes a passos lentos, dando muitas vezes dúvidas com relação ao exercício da função.

Essa ideia foi tema da sexta oficina ("Debate sobre papéis dos profissionais"), que teve por objetivo discutir o que os profissionais da unidade fazem a partir da visão dos agentes de saúde, a fim de conhecer o que os ACS pensam e elaborar a própria função do agente, sobrecarregada de atividades e pouco valorizada pelo grupo em termos de mudanças comunitárias. Como disparador, foi construída uma história, um relato de uma família que há pouco chegara à região circunscrita à unidade, com diversas questões-problemas. Cada agente faria o papel de um profissional que compõe a equipe da ESF e diria o que fazer, de acordo com a profissão representada.

A troca de informações permitiu esclarecer funções específicas de cada profissional, trabalhar preconceitos sobre algumas profissões, perceber crenças e ideias que aprisionavam a prática do grupo. Entretanto, uma das mais importantes contribuições da atividade foi possibilitar a compreensão por parte dos agentes sobre a importância da própria profissão e sua atuação na equipe de saúde. Neste período, foi observada uma participação mais efetiva daqueles que permaneciam no grupo e maior interesse por trabalhar e defender as próprias questões.

Nas sétima e oitava oficinas foram vistos e lidos pelos ACS fragmentos de textos extraídos de Silva e Dalmaso (2002), Tomaz (2002) e Wai (2007), que debatiam a respeito do trabalho do agente comunitário de saúde, seu sofrimento, fatores de sobrecarga e mecanismos de enfrentamento destes. 0 material trazia relatos de pesquisas realizadas com ACS em outros estados, contudo, trazendo situações e experiências bastante parecidas com aquelas vivenciadas pelo grupo.Referindo-se aos fatores de sobrecarga e aos mecanismos de enfrentamento citados por Wai (2007) acerca dos ACS, muitos agentes se identificaram com o relato, afirmando que este poderia ser uma cartilha dos agentes comunitários de saúde. A leitura tornou-se facilitadora por retratar muitas questões vivenciadas no trabalho dos agentes, que são próprias da função e não específicas da unidade. Os estagiários identificam que era hora de iniciar as 
buscas por algo mais prático para fazer no grupo, principalmente tendo em vista o trabalho que estava sendo realizado.

O desenvolvimento da atividade a partir da leitura dos trechos tornou-se facilitador no sentido de desmistificar os problemas antes vistos como específicos daquela unidade, quando na realidade eram características próprias da profissão. Desta maneira seria então possível pensar em estratégias de enfrentamento e construir intervenções para que lidassem com os problemas sob uma nova perspectiva, mais ativa, diferente da posição em que se colocavam até o momento diante das dificuldades.

\section{Quadro 3-Fase 3-Solidificando as mudanças}

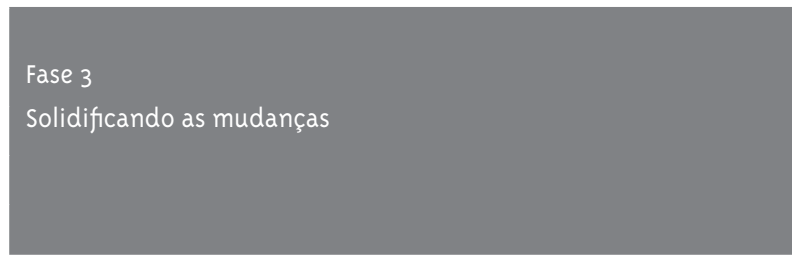

Nas oficinas seguintes, relativas à terceira fase, de solidificação das mudanças, foram debatidas ações construídas pelos agentes com o intuito de melhorar as condições de trabalho, a interação entre si e com os demais profissionais da unidade e moradores da comunidade. Algumas dessas ações, pensadas a partir da reflexão dos dados encontrados por Wai (2007), e outras de acordo com as experiências das próprias.

Os debates sobre o trabalho trouxeram à tona dilemas internos do grupo e dificuldades na interação que passaram a ser discutidas e postas em questão. Era perceptível a diferença nas reclamações feitas pelo grupo, antes soltas, sem objetivos e desmotivantes, e depois focadas, claras, propositivas e estimulantes, demonstrando crescimento e maturidade do grupo.

Alguns agentes comentaram a diferença da participação nas atividades e eventos voltados para a saúde e relataram o aumento da participação das pessoas do grupo.

Nas últimas oficinas, os agentes trouxeram preocupações, ansiedades e esperanças quanto a algumas mudanças no trabalho, como a troca da
Pode-se inferir que no processo de intervenção, mais especificamente a partir desse momento, os agentes passaram a perceber que os problemas, antes dificultadores e exclusivos, que também são compartilhados por outros grupos (ACS de outras localidades), passaram a atuar como elemento motivador para o início do movimento de mudança no grupo. Esse movimento passa a ser responsável por um novo sentido de ser Agente Comunitário de Saúde, como algo de pertencimento à profissão, ou seja, passa a fazer parte do processo de mudança, reconstruindo a identidade desses participantes, como pode ser observada na Fase 3.
Oficina ॥ - Elaboração de ações em equipe

Oficina 12 - Historização do grupo de ACS

Oficina 13 - Debate sobre ideias e ações das ACS

Oficina 14 - Avaliação das ACS sobre as ACS

Oficina 15 - Avaliação das oficinas de psicologia chefia do programa (pessoas novas no trabalho) e também a possibilidade de construir caixas de sugestões para avaliar os serviços da unidade. Também citaram a importância de serem construídos cadernos de avaliação geral das ações da unidade. Relataram a busca de melhores condições para o trabalho, como guarda-chuvas e capas de chuva, sapatos mais confortáveis, dentre outros. Uma outra preocupação dizia respeito à avaliação de fim de ano, em que seria definido sobre a renovação ou não do contrato de trabalho.

De acordo com o relato dos participantes, os ACS que se mantiveram participando das oficinas obtiveram algumas conquistas, principalmente em relação a aspectos comuns do dia a dia do trabalho, que eram deixados de lado, não recebendo atenção devida. Esses e outros relatos foram feitos na avaliação das oficinas, ocorrida no último dia de atividade.

O grupo como espaço de fala, sem cobranças, sem preconceitos, foi citado mais de uma vez na avaliação, indicando que este espaço permite que se fale das angústias, dos estresses, dos problemas do dia a dia que interferem diretamente na qualidade do trabalho sem que haja punições ou exigências ex- 
cessivas. Juntamente, situaram a intervenção como algo importante para pensar o trabalho, a atuação profissional, tendo como principais benefícios a promoção de reflexões, elaboração dos conflitos, construção de estratégias e outros modos de agir.

\section{Considerações Finais}

O desenvolvimento da atividade, na UBS, junto aos agentes permitiu a elaboração de ideias tanto dos profissionais quanto dos estagiários que ali propunham um trabalho. As 15 oficinas se mostraram fundamentais na construção de um diagnóstico e de uma leitura do grupo e na realização dos projetos planejados de acordo com as situações percebidas.

Várias foram as avaliações realizadas pelos agentes no decorrer dos encontros, julgando-os positivos e importantes, trazendo reflexões e mudanças como, por exemplo, as modificações observadas no próprio grupo, que passou a buscar objetivos comuns, a ter mais força, união, compreensão com o outro, leveza, coragem de falar. Comentários como "houve mudanças, saímos de piores da unidade a profissionais de saúde", "agora todo mundo tá interessado [em participar dos eventos que aparecem]" (falas de agentes na oficina 15), demonstram as mudanças percebidas pelos agentes no decorrer das atividades, muitas vezes por terem refletido e buscado outras possibilidades.

O grupo parecia enfraquecido no início das atividades, impotente para realizar mudanças, para pensar no próprio trabalho. Com o desenvolvimento do processo de intervenção foi possível para o grupo criar uma ideia positiva para si, potencializando e dando um novo sentido à sensação de impotência observada nos primeiros encontros.

Retomamos Silva e Dalmaso (2002) para discutir a respeito da identidade do ACS. Segundo as autoras, é possível identificar quatro blocos temáticos acerca da identidade deste profissional: o primeiro relacionado à profissão, sua relação com o saber e a regulamentação; o segundo relacionado à organização do trabalho, das regras e respaldo social; o terceiro relacionado à identidade no pertencer a determinado grupo; e, por último, as características assistenciais na saúde e as funções dos profissionais.

A análise desses eixos de identidade coloca o agente entre dois polos, o institucional e o político, ou, de outra maneira, entre o agente institucional e o de comunidade. Quando o agente incorpora esses dois eixos, o conflito se torna inevitável. Este aspecto se dá sempre que se pretende trabalhar esse profissional como representante de seu grupo de origem, que é a comunidade. Implica, assim, não apenas as relações de trabalho e institucionais na Unidade de Saúde, mas suas relações políticas na comunidade, tendo em vista que o agente é um representante da mesma. Apesar disso, o foco, ainda assim, tende a prevalecer no campo institucional, o que, acreditamos, manterá em suspenso a questão da identidade do agente e a tensão em função de sua formação hibrida (Silva e Dalmaso, 2002).

Em contraposição, porém, também pensando numa melhor forma de lidar com a situação, sustentamos a importância de tais espaços de fala, focados não apenas no trabalho como também na constituição de crenças, percepções, impressões do grupo de agentes a respeito de si, da unidade e da comunidade, juntamente com debates a respeito de suas experiências e vivências no tocante àquilo com que interagem no dia a dia. O foco sai necessariamente do agente como técnico e membro da comunidade e passa para o agente como participante do grupo de agentes de determinada unidade e comunidade.

Uma das dimensões de identidade citadas por Silva e Dalmaso (2002), o terceiro bloco temático, refere-se ao pertencimento a um determinado grupo diferenciando-se dos demais grupos por ter certa congruência e vinculação interna forte.

Tal ideia de identidade pode ser comparada com aquela proposta por Tajfel (1981, p. 255), segundo o qual identidade social é "aquela parte do autoconceito dos indivíduos que deriva do seu conhecimento sobre sua relação [pertença] com um grupo social (ou grupos) junto com o valor e significado emocional daquela relação [pertença]", e se constrói a partir das referências que os participantes deste grupo têm do mesmo, em relação aos demais.

Comumente quando estas referências são positivas, valorizam o próprio grupo internamente, produzindo pertença. Porém, há casos em que o grupo se referencia em fatores negativos, prejudicando a si, evitando que saia do lugar, mantendo-se impotente e incapaz. Nesses casos ainda é possível buscar valo- 
res, atitudes, crenças mais positivas, que permitam ao grupo se potencializar, modificando e aumentando o sentimento de pertença (Senos, 1997).

Entendemos a formação da identidade social como fundamental na constituição de determinado grupo para a sustentação de dificuldades algumas vezes inerentes à própria formação do grupo. A identidade social, assim, coloca-se como possibilidade de o grupo se sentir fortalecido, enfrentando suas tensões a partir do sentimento de pertença ao próprio grupo, ao invés de rejeitar as crises pelas quais passa.

Na avaliação final do trabalho apareceram conteúdos relativos às transformações observadas pelos participantes. Falas relacionadas à possibilidade de desabafar, de falar aquilo que nem sempre é permitido, de se expressar com liberdade e sem cobrança, sendo tratados com amor, carinho e proteção foram descritas na avaliação. Juntamente com estas, falas relativas ao grupo mostravam percepções de união, leveza, crescimento interno, mais força, felicidade e abertura, ao contrário do que fora encontrado no início das oficinas. Surgiram falas, como, por exemplo: "[...] o grupo descobriu vários meios de se integrar, de interagir", "O grupo que participou com certeza cresceu e contribui para algumas mudanças", "Mais unido para resolver um problema em comum", "Houve uma melhora com relação à busca pelos objetivos em comum, antes esta união era mais difícil" (Avaliação de agentes na Oficina 15).

0 grupo como espaço de fala permitiu a construção de um ambiente favorável, respeitoso e confiante. Os agentes construíram novas representações sobre si e sobre o grupo, tendo a liberdade para expressar seus sentimentos e pensamentos entre si. Fica clara a importância de o grupo permanecer junto e ter espaços próprios para a reflexão e elaboração das situações vivenciadas cotidianamente, de maneira tal que consiga não apenas reconstruir as relações de trabalho, mas as percepções sobre seu próprio grupo, seus papéis, sua identidade social.

Assim, tomando por base a leitura do grupo pelos dados discutidos, torna-se possível pensar a identidade deste personagem ACS, ao contrário de Silva e Dalmaso (2002), não simplesmente a partir das dimensões do trabalho, mas, também, pela dimensão da identidade social, identidade do grupo de ACS que participa de uma unidade de saúde e de uma comunidade. Pela via da profissão, o grupo parece apresentar sinais de angústia. Isso se deve, provavelmente, por ser uma profissão híbrida, sem uma identidade solidificada. Por outro lado, pensando os agentes não pela profissão, mas pelo grupo de agentes e sua pertença a este grupo, é possível fortalecer as pessoas para que consigam lidar tanto com os sinais de angústia quanto com outras adversidades que se apresentem.

Não se pode dizer, portanto, que questões que envolvam a interação entre a unidade e a comunidade na vida dos ACS e a interação entre os fatores técnicos e políticos na gestão do SUS deixarão de existir. 0 que pode ser apontado é o fato de que sempre haverá tal ambiguidade, e se ela gerará ou não sofrimento dependerá da maneira como cada pessoa elaborará as mudanças visando fortalecer a identidade pessoal e grupal. Dessa forma, a intervenção aqui descrita demonstra que é possível construir dentro dos grupos de agentes, certos vínculos que fortaleçam suas escolhas diariamente. Vínculos que permitam discutir, conversar, construir ideias, valores e trocar afetos, entre outros, que reduzam a angústia e possibilitem a construção de uma identidade minimamente estruturada como base de sustentação para os outros tipos de identidade.

Terminadas as oficinas e as ações, resta pensar como estará o grupo em sequência, como se organizará, como se disporá a continuar refletindo o trabalho, buscando estratégias. Parte-se do princípio de que o grupo não será como antes, por se responsabilizar em construir novas normas, mais produtivas e funcionais, e tem-se a certeza de que houve mudanças nas formas de interação e elaboração das agentes, que se mostraram mais implicadas com suas questões. Significa dizer que a identidade desse grupo específico de agentes sofreu mudanças de acordo com os novos posicionamentos feitos pelos profissionais, não voltando àquilo que era, mas tendo a possibilidade de sempre estar se modificando, permitindo que trabalhem em melhores condições dentro do grupo, construindo nova pertença e também estratégias para lidar com as situações fora dele, na unidade e na comunidade.

Por fim, cabe também à Psicologia criar espaços de discussão entre os profissionais de saúde, espa- 
ços que permitam novos encontros, a construção de saberes, a elaboração de conflitos e angústias, de identidades e outros aspectos importantes para a construção de uma qualidade de vida no trabalho e de um trabalho saudável a quem nele trabalha.

\section{Referências}

BORNSTEIN, V. J.; STOTZ, E. N. Concepts involved in the training and work processes of community healthcare agents: a bibliographical review.

Ciência e Saúde Coletiva, Rio de Janeiro, v. 13, n. 1, p. 259-268, 2008. Disponível em: <http://www. scielo.br/scielo.php?script=sci_arttext\&pid=S1413$81232008000100029 \& \operatorname{lng}=e n \& n r m=i s o>$. Acesso em: 22 jun. 2008.

CANGUILHEM, G. O normal e o patológico. Rio de Janeiro: Forense Universitária, 1990.

CZERESNIA, D. O conceito de saúde e a diferença entre prevenção e promoção. In: CZERESNIA, D.; FREITAS, C. M. (Org.). Promoção da saúde: conceitos, reflexões, tendência. Rio de Janeiro: Fiocruz, 2003. p. 39-53.

JARDIM, T. A. Morar e trabalhar na comunidade: a realidade dos agentes comunitários de saúde. 2007. Dissertação (Mestrado em Ciências)Faculdade de Medicina da Universidade de São Paulo, São Paulo, 2007.

KLUTHCOVSKY, A. C. G. C.; TAKAYANAGUI, A. M. M. O agente comunitário de saúde: uma revisão da literatura. Revista Latino-Americana de Enfermagem, Ribeirão Preto, v. 14, n. 6, 2006. Disponível em: <http://www.scielo.br/ scielo.php?script=sci_arttext\&pid=So104$11692006000600019 \& \operatorname{lng}=p t \& n r m=i s o>$. Acesso em: 22 jun. 2008.

MARTINES, W. R. V.; CHAVES, E. C. Vulnerabilidade e sofrimento no trabalho do agente comunitário de saúde no Programa de Saúde da Família. Revista da Escola de Enfermagem da USP, São Paulo, v. 41, n. 3, set. 2007. Disponível em: <http://www.scielo. br/scielo.php?script=sci_arttext\&pid=Soo8o$62342007000300012 \& \operatorname{lng}=e n \& n r m=i s o>$. Acesso em: 23 jun. 2008.
NEGRI, B. Introdução: a política de saúde no Brasil nos anos 1990: avanços e limites. In: NEGRI, B.; VIANA, A. L. (Org.). O Sistema Único de Saúde em dez anos de desafios. São Paulo: Sobravime: Cealag, 2002. p. 15-42.

NUNES, M. O. et al. Community-based health workers: building the identity of this hybrid, polyphonic character. Cadernos de Saúde Pública, Rio de Janeiro, v. 18, n. 6, dez. 2002. Disponível em: <http://www.scielo.br/ scielo.php?script=sci_arttext\&pid=So102311X2002000600018\&lng=en\&nrm=iso >. Acesso em: 22 jun. 2008.

SENOS, J. Identidade social, auto-estima e resultados escolares. Análise Psicológica, Lisboa, v. 15, n. 1, p. 123-137, 1997. Disponível em: <http://www.scielo.oces.mctes.pt/ scielo.php?script=sci_arttext\&pid=So870$82311997000100010 \& \operatorname{lng}=p t \& n r m=i s o>$. Acesso em: 03 ago. 2008.

SILVA, J. A.; DALMASO, A. S. W. Agente comunitário de saúde: o ser, o saber, o fazer. Rio de Janeiro: Fiocruz, 2002.

SOUZA, H. M. Saúde da família: desafios e conquistas. In: NEGRI, B.; VIANA, A. L. (Org.). $O$ Sistema Único de Saúde em dez anos de desafios. São Paulo: Sobravime: Cealag, 2002. p. 221-240.

SPINK, M. J. P. Psicologia social e saúde: práticas, saberes e sentidos. Petrópolis: Vozes, 2003.

TAJFEL, H. Grupos humanos e categorias sociais. Lisboa: Livros Horizonte, 1981.

TOMAZ, J. B. C. O agente comunitário de saúde não deve ser um "super-herói”. Interface: Comunicação, Saúde, Educação, Botucatu, v. 6, n. 10, p. 75-94, 2002. Disponível em: <http:// redalyc.uaemex.mx/src/inicio/ArtPdfRed. jsp?iCve=180114097008>. Acesso em: 3 ago. 2008. VASCONCELOS, C. M.; PASCHE, D. F. O Sistema Único de Saúde. In: CAMPOS, G. W. S et al. (Org.). Tratado de saúde coletiva. São Paulo: Hucitec; Rio de Janeiro: Fiocruz, 2006. p. 531-562. 
WAI, M. F. P. O trabalho do agente comunitário de saúde na estratégia saúde da família: fatores de sobrecarga e mecanismos de enfrentamento. 2007. Dissertação. (Mestrado em Enfermagem Psiquiátrica)-Escola de Enfermagem de Ribeirão Preto da Universidade de São Paulo, São Paulo, 2007. 